\title{
"EL ORBE ES UNA REPÚBLICA" (LA TRADICIÓN INTERNACIONALISTA MEXICANA)
}

El derecho internacional es la primera gran construcción del derecho público moderno. El Estado renacentista no alentó un concepto de derecho constitucional, pero sí generó numerosos principios que configuraron el derecho de gentes. Aunque desde la perspectiva constitucional se identifican algunos precedentes en el medievo, como la carta magna, lo cierto es que los primeros esfuerzos doctrinarios encaminados a la sistematización del derecho estatal se refirieron a las normas que hoy consideramos propias del derecho internacional.

No fue accidental que la primera gran concepción del Estado moderno haya sido formulada precisamente por un avezado diplomático e historiador. Maquiavelo dejó ver muy claramente la importancia de dos factores que condujeron a la configuración del Estado. Uno, de carácter endógeno, correspondía a la necesidad de concentrar el poder que, a partir de la caída de imperio romano, había perdido cohesión. La Edad Media, como bien se sabe, había experimentado un acentuado proceso de fragmentación del poder, y aunque no es posible abundar aquí acerca de las múltiples razones culturales, económicas y políticas que llevaron a la reconstrucción del poder centralizado y coactivo a la que denominamos Estado, sí se puede afirmar que todas ellas fueron advertidas con claridad por la gran literatura política del siglo XVI. En particular fueron cruciales, además de la obra Maquiavelo, los notables textos de Hobbes y Altusio.

El otro factor que contribuyó al nacimiento del Estado moderno y que ya se advierte en los razonamientos maquiavelinos, fue de carácter exógeno. El Estado moderno no sólo se construyó merced a las motivaciones interiores; emergió también impulsado por el desafío que representaban las acciones de defensa, expansión y conquista emprendidas en diferentes proporciones por los Estados nacientes.

En medio de ese panorama, la inesperada presencia americana en Europa aceleró el proceso de ruptura con la Edad Media. Un nuevo grupo humano, una nueva fuerza cultural y una nueva geografía produjeron un 
importante impacto en el espacio europeo, en un momento en el que las artes y la ciencia ya habían comenzado a experimentar profundas transformaciones a partir del siglo XV. "Fue el Nuevo Mundo lo que repercutió primariamente sobre el mundo humano todo y la idea de él", ha demostrado Gaos (p. 230). El descubrimiento de América contribuyó a su vez al "descubrimiento", o más propiamente a la "invención” de Europa. Hale (pp. 47 y ss.) sustenta que "gracias a la suprema confianza que les inspiró el descubrimiento de América, los europeos hicieron un mayor esfuerzo por plantearse la cuestión de su identidad". La fuerza del contraste y la conciencia de haber encontrado un mundo nuevo también ayudaron a poner fin a la fragmentación medieval.

Los requerimientos de defensa, expansión y conquista en el siglo XVI trajeron asimismo otra importante consecuencia: la búsqueda y, desde luego, el hallazgo de los fundamentos jurídicos para la acción del Estado. De ahí que las expresiones iniciales del Estado de derecho correspondan al derecho de gentes; formaron parte del orden normativo internacional antes que del nacional.

La obra que sintetiza esas poderosas fuerzas generadoras del nuevo orden jurídico es la de Vitoria, justamente reconocido como el "padre del derecho internacional moderno” (Gómez Robledo, El ius cogens..., p. 17). Las Relecciones de indios y del derecho de guerra fueron objeto de una amplia y rápida difusión en Europa. A la primera edición de Lyon, de 1557, siguieron la de Salamanca, de 1565, otras dos francesas de 1586 y 1587, y las de Amberes, de 1604, Venecia, de 1626 y 1640, y las más tardías de Colonia y Francfort, de 1696. Las ideas de Vitoria encontraron numerosos lectores en España, Italia, Francia y los Estados germanos.

Aunque el tema no fue desarrollado con amplitud, en las obras de César Sepúlveda (p. 19) y Antonio Gómez Robledo (Fundadores..., pp. 8 y ss.), se advierte la coincidencia entre el surgimiento del derecho internacional y el descubrimiento de América. No se trata, por supuesto, de la única causa de que apareciera esa disciplina, pero sin duda constituyó un factor relevante para impulsar su rápido desarrollo y su importante consolidación doctrinaria. En tanto que España desempeñó un papel predominante en el proceso de expansión territorial, no sorprende que entre los cuatro fundadores del derecho internacional, como los llama certeramente Gómez Robledo, figuren dos españoles: Francisco de Vitoria y Francisco Suárez. 
Corresponde a Miguel León Portilla el afortunado concepto del "encuentro de dos mundos". Europa sólo fue consciente de su identidad continental a partir del hallazgo de las nuevas tierras y del cotejo con razas y culturas hasta entonces desconocidas. Es a partir del siglo XVI cuando el concepto de Europa se desarrolla con vigor. Aparecen una nueva cartografía y numerosas obras referidas expresamente a temas "europeos". Hubo incluso quien sugirió cambiar al nombre del continente, porque el de "Europa" implicaba una especie de tributo a las relaciones entre un animal y una mujer.

El gentilicio "europeo" es, comprensiblemente, posterior al constructo "Europa". En inglés y en español los primeros registros de la utilización de ese gentilicio corresponden al siglo XVI, y sólo se generaliza al principiar el XVII (véase Knolles y Ovalle, por ejemplo). Hasta antes del descubrimiento (y en los escritos de Vitoria todavía se conserva la expresión) se hablaba de "cristianos", no de "europeos", así como de la "cristiandad", como el conjunto de países que corresponde a Europa.

La historiografía propiamente referida a "Europa" también corresponde al siglo XV. La historia general de Blondus, que comprende de 472 a 1440, publicada en Venecia en 1483, todavía se denomina Historiarum ab inclinatione romanorum imperii decades. La primera alusión a Europa aparece en la obra de Eneas Silvio Piccolomini, publicada en 1490. Fueter (t. I, p. 130) subraya que esta obra póstuma de Silvio, escrita en Bohemia, quedó inconclusa. En todo caso su contenido es fundamentalmente lexicográfico y geográfico, por lo que se explica la referencia a "Europa". Además, Silvio, ungido como Pío II en 1458, fue considerado un papa dotado de excepcional erudición y elocuencia (Ranke, pp. 33 y ss.), cuyo interés por la cultura continental quedó demostrado por sus hábitos de viajero y de lector infatigable. En buena medida Silvio es un auténtico renacentista y, en el tema que nos ocupa, un precursor. En realidad las primeras obras que directamente incluyen en su denominación y contenido el concepto europeo, corresponden ya al siglo XVI.

Por lo que respecta a México, la polémica entre Bartolomé de las Casas y Ginés de Sepúlveda, en el siglo XVI, fue el preludio de un largo debate que si bien en su inicio estuvo centrado en los derechos de los indios, progresivamente derivó hacia las consideraciones generales de lo que ahora denominamos derechos fundamentales. La génesis de estos derechos en nuestro sistema constitucional se encuentra, por lo mismo, en disputas jurídicas y doctrinarias que se dieron como parte del derecho de 
gentes. Al proscribirse la esclavitud, por bando de Miguel Hidalgo, en 1810, y adoptarse las primeras normas tutelares de las libertades en la Constitución de Apatzingán, en 1814, culminaba un proceso del que puede considerarse precursor a Las Casas.

El derecho constitucional y el internacional se fueron separando cuando el primero se orientó a la consolidación de las libertades individuales y colectivas, y el segundo a la definición de las identidades nacionales. Ambos han mantenido, empero, un punto fundamental de contacto: la organización y el funcionamiento del poder. Ambas expresiones normativas se fundamentan en los conceptos de soberanía popular y de soberanía nacional, en buena medida complementarios. Por lo general el derecho constitucional y el derecho internacional suelen ser estudiados de manera separada, en tanto que progresivamente se fueron diferenciado en cuanto a sus contenidos y objetivos. Esto no obstante, la temprana incorporación de los derechos humanos en el constitucionalismo británico, norteamericano y francés, es el resultado de la influencia directa del derecho de gentes en el ámbito constitucional.

En la actualidad no se puede desconocer que ese origen común de ambas vertientes normativas, genera tensiones. La idea de la llamada globalización es, en buena medida, una forma, pretendidamente nueva, de argumentación a favor de la prevalencia del derecho internacional sobre el nacional; en realidad se trata de la tesis fundante del derecho internacional. La denominada globalidad a la que con tanta insistencia se hace referencia en nuestros días, no es ajena a la tradición clásica del derecho internacional.

Del visionario Francisco de Vitoria tomé la expresión que encabeza este texto: "el orbe es una República" (p. 307). Para tener una idea aún más precisa de los alcances de esa idea, debe considerarse que en su época todavía no se generalizaba la utilización de la voz "Estado", que por lo demás no aparece en los escritos del profesor salmantino. Durante un largo periodo (así lo demuestra Gómez Robledo, Fundadores..., p. 14), numerosos autores, utilizaron la voz "república" en un sentido semejante al de "Estado". De ahí el extendido alcance de la expresión vitoriana, "el orbe es una República".

El derecho de gentes, según sostiene Vitoria en La potestad civil y en las Relecciones, está constituido por "leyes equitativas y convenientes a todos", y por lo mismo es aplicable entre todas las naciones (p. 145). Ahí encontramos la génesis conceptual de lo que en nuestro tiempo corres- 
ponde al más importante movimiento de renovación institucional, estatal e interestatal: el reconocimiento y defensa de los derechos humanos, cuya proyección internacional es uno de sus rasgos más característicos. Incluso los nuevos contenidos de estos derechos, como los concernientes a la información y a las minorías, por ejemplo, no son sino expresiones contemporáneas de un conjunto de principios y disposiciones que tienen su origen en el derecho de gentes.

En el caso de México, diversos instrumentos del derecho internacional preceden a los constitucionales como garantías de la libertad. Pero no sólo eso. Incluso en nuestros días se reconoce que en esas disposiciones internacionales existe una suma de derechos fundamentales que amplían significativamente los que consagra la Constitución. No obstante, y en virtud del artículo 133, esos tratados y convenciones también forman parte del orden normativo nacional. Casos muy relevantes son los representados por el Convenio 169 de la Organización Internacional del Trabajo, cuyas previsiones en materia de derechos de los indígenas son más amplias que las contenidas en el artículo 4o. constitucional, y la Convención Americana sobre Derechos Humanos, que contiene, entre otras, prevenciones en cuanto al derecho a la información que aún no recoge la Constitución mexicana. Con todo, y según lo previsto en el ya mencionado artículo 133, las normas internacionales suscritas por el Estado mexicano son aplicables en el territorio nacional.

El derecho internacional, por ende, sigue siendo una fuente de modernización del orden jurídico interno. Esto también explica los alcances de la obra de los internacionalistas mexicanos, en especial los más sobresalientes del siglo XX: Isidro Fabela, César Sepúlveda, Antonio Gómez Roledo y, aunque su obra haya sido eminentemente histórica y literaria, pero cuyas aportaciones en materia de política exterior resultaron cruciales, Genaro Estrada. A ellos debe sumarse una formidable capacidad diplomática y política a lo largo de nuestra vida independiente, representada por los cancilleres. Para mencionar sólo a quienes ya forman parte de la historia, pueden invocarse los ejemplos de figuras como Lucas Alamán, Manuel Crescencio Rejón, Melchor Ocampo, Sebastián Lerdo de Tejada e Ignacio L. Vallarta, en el siglo XIX; y Manuel Tello y Jorge Castañeda, que simbolizan en el siglo XX la profesionalización del trabajo diplomático.

Todo lo anterior se ha tenido en cuenta para que el Instituto de Investigaciones Jurídicas abra, a través de esta nueva publicación, un espacio adicional para que siga prosperando la rica tradición internacionalista del 
país. El Anuario, cuyo primer número tiene ahora en sus manos el lector, es el resultado de una lúcida iniciativa de Manuel Becerra y del decidido apoyo de los distinguidos expertos, mexicanos y extranjeros, que generosamente aceptaron integrar el Consejo Editorial.

Una publicación de este género supone un compromiso académico de gran calado. El propósito es presentar materiales de análisis y de información suficientemente representativos del quehacer jurídico internacional. No es tarea fácil, si se tiene en cuenta la dinámica actividad que se registra en ese campo. A pesar de tratarse de una disciplina ya longeva, sigue mostrando los signos de una vitalidad excepcional. Disciplina germinal, el derecho internacional es también tributario de prácticamente todas las áreas del derecho que han venido apareciendo.

La intensa interacción de todas las entidades estatales y de todas las sociedades nacionales da sentido, en el siglo XXI, a la longeva idea de Vitoria. El orbe, en efecto, es una República. En este caso, por supuesto, República ya no debe entenderse como sinónimo de Estado sino como comunidad de intereses relevantes. Esos intereses relevantes tienen expresiones equivalentes para la comunidad internacional y para las comunidades nacionales. Los principios de derecho internacional recogidos por la fracción X del artículo 89 constitucional encuentran correspondencia en los de naturaleza análoga que rigen en el ámbito interno: solidaridad, acceso a la justicia, distribución de la riqueza, vigencia del Estado social y democrático de derecho. En ese entendido, la fuerte interacción entre los Estados del orbe no implica que la soberanía de cada nación decline ni que la identidad de cada cultura mengüe.

Invoco a Vitoria para acreditar un proceso secular consolidado, como podía haber recurrido al ejemplo de las tesis anfictiónicas helénicas para subrayar que todo, o casi, en el mundo de la cultura forma parte del pensamiento clásico. La naturaleza orbital de los intereses humanos no es cosa nueva ni negativa. Lo nuevo es creer que lo clásico se acaba de inventar; pero este es un error menor. La cultura - el derecho y la política son dos de sus expresiones más relevantes - siempre ha tenido vocación de universalidad.

El Instituto de Investigaciones Jurídicas de la Universidad Nacional Autónoma de México ha contado siempre con distinguidos expertos en derecho internacional, como se acredita con la producción bibliográfica generada en esta materia. Ahora desea seguir contribuyendo al enriquecimiento de esta disciplina inagotable con la publicación de un Anuario me- 
xicano que hará posible el trabajo de la actual generación de internacionalistas; generación que previsiblemente engrandecerá la ya admirable tradición internacionalista mexicana.

\section{FUENTES}

FUETER, E., Historia de la historiografía, Buenos Aires, Nova, 1953.

GAOS, José, Historia de nuestra idea del mundo, México, Fondo de Cultura Económica, 1973.

GÓMEZ-ROBLEDO, Antonio, Fundadores del derecho internacional, México, UNAM, 1989.

—_, El ius cogens internacional, México, UNAM, 1982.

HALE, John, La civilización del Renacimiento en Europa (1450-1620), Barcelona, Crítica, 1996.

KNOLLES, Richard, The General Historie of the Turkes, Londres, Adam Islip, 1621.

Ovalle, Alfonso de, Histórica relación del reino de Chile, Roma, F. Cavallo, 1646 .

RANKE, Leopold von, Historia de los papas, México, Fondo de Cultura Económica, 1943.

SEPÚLVEDA, César, El lugar del derecho internacional en el universo jurídico, México, Porrúa, 1989.

VITORIA, Francisco de, Relecciones de indios y del derecho de guerra; La potestad civil, Madrid, Espasa Calpe, 1928

Diego Valadés

Director del Instituto de Investigaciones Jurídicas

Ciudad Universitaria, primavera de 2001 